\title{
IDIOPATHIC PULMONARY ARTERY ANEURYSM (PAA) MIMICKING AS CAVITY, A RARE ENTITY
}

\author{
A. P. Kansal11, Deepak Goyal², Naresh Kumar 3 , Daksh Jhim ${ }^{4}$ \\ 1 Professor and HOD, Department of Chest and T.B, Government Medical College, Patiala. \\ ${ }^{2}$ Senior Resident, Department of Chest and T.B, Government Medical College, Patiala. \\ ${ }^{3}$ Senior Resident, Department of Chest and T.B, Government Medical College, Patiala. \\ ${ }^{4}$ Junior Resident, Department of Chest and T.B, Government Medical College, Patiala.
}

\begin{abstract}
Aneurysms of Pulmonary Arteries (PAs) and trunk are rare. Infection, structural cardiac anomalies, structural vascular anomalies and pulmonary hypertension are among the most common underlying risk factors for developing Pulmonary Artery Aneurysms (PAAs). Idiopathic, isolated aneurysms also do occur, but they are very rare entity. Owing to advances in diagnostic imaging methods such as Computed Tomography (CT), Magnetic Resonance Imaging (MRI) and echocardiography, nowadays reports and identification of these clinical entities have increased. We report a 62-year-old female presented to our outpatient department with complaint of haemoptysis and was diagnosed to have left Pulmonary Artery Aneurysm (PAA).
\end{abstract}

\section{KEYWORDS}

Pulmonary Artery, Pulmonary Artery Aneurysm, Pulmonary Angiography.

HOW TO CITE THIS ARTICLE: Kansal AP, Goyal D, Kumar N, et al. Idiopathic pulmonary artery aneurysm (PAA) mimicking as cavity, a rare entity. J. Evolution Med. Dent. Sci. 2016;5(32):1768-1770, DOI: 10.14260/jemds/2016/416

\section{INTRODUCTION}

Pulmonary artery aneurysm (PAA) is a rare entity, isolated or idiopathic PAA is even less common. The specific prevalence of PAA is unknown, but it was reported in 1 out of every 14000 autopsies. ${ }^{1,2}$ PAA is described as a dilatation of Pulmonary Artery (PA). ${ }^{3}$ Although, there is no accurate definition for PAA, some studies have mentioned $4 \mathrm{~cm}$ of diameter as a cut-off point. ${ }^{3}$ Subsequent studies reported the upper normal limit of main Pulmonary Artery (PA) diameter is $29 \mathrm{~mm}$ on Computed Tomography (CT). ${ }^{4}$ Association with structural cardiac anomalies, structural vascular anomalies, pulmonary hypertension, vasculitis and infection has been noted. Most patients with pulmonary artery aneurysm are asymptomatic. ${ }^{5}$ Symptomatic patients may present with nonspecific complaints including mild dyspnoea generally on exertion, fever, cough, haemoptysis. ${ }^{6}$ We present an idiopathic PAA case with haemoptysis at baseline. Non-invasive imaging techniques including Magnetic Resonance Imaging (MRI) and CT can help clinician in diagnosis, but the gold standard diagnostic tool for PAA is pulmonary angiography. 1,4

\section{CASE SUMMARY}

A 62-year-old female presented to our outpatient department with complaint of haemoptysis. There were two episodes of haemoptysis with approximately $300 \mathrm{~mL}$ of blood expectorated. There was no history of similar episode in past. There was no complaint of cough, breathlessness or fever. She was diabetic and on oral hypoglycaemic treatment for the last 5 years. General physical examination revealed anaemia. Her heart rate was 116 beats per minute, regular in rhythm; blood pressure was 130/80 $\mathrm{mmHg}$, respirations 18 breaths per minute.

Financial or Other, Competing Interest: None.

Submission 02-03-2016, Peer Review 29-03-2016,

Acceptance 04-04-2016, Published 21-04-2016.

Corresponding Author:

Dr. Daksh Jhim

\#268, New Subhash Nagar,

Maqsudan, Jalandhar-144008,

Punjab.

E-mail: djdakshjhim@gmail.com

DOI: $10.14260 /$ jemds $/ 2016 / 416$
Cardiovascular examination revealed no abnormality. Auscultation of the lungs revealed bilateral vesicular breath sounds with equal intensity. Laboratory evaluation revealed haemoglobin $7.3 \mathrm{~g} / \mathrm{dL}$; TLC - 10,400/cumm with neutrophilic predominance (72\%). Venereal Disease Research Laboratory (VDRL) test for syphilis and collagen profile was also negative. The chest radiograph revealed a left middle zone cavity with surrounding consolidation (Figure 1). Electrocardiogram (ECG) was suggestive of sinus tachycardia with left axis deviation. Two-dimensional (2D) transthoracic echocardiography demonstrated IVS posterior wall mismatch, right ventricular free wall hypokinesia, ejection fraction $49.7 \%$ and normal cardiac valve morphology.

There were no signs of intracardiac shunt. ContrastEnhanced Computed Tomography (CECT) of thorax (Figure 2 and 3) showed a well-defined fluid attenuation lesion containing multiple air loculi and surrounded by collapsed lung parenchyma $(5 \times 5.3 \mathrm{~cm}$ MAD) in left lower lobe. This lesion contains a hypodense lesion, which fills on contrast and is seen as focal dilatation of a branch of left pulmonary artery.

This lesion measures $28 \times 18 \mathrm{~mm}$ (in MAD) suggestive of aneurysm. The rest of the mediastinal structures were within normal limits. Further investigations did not show any disorder that could lead to the aneurysmal dilatation of the pulmonary artery. Thus, a diagnosis of idiopathic aneurysm of the main pulmonary artery was made. Patient was referred to higher centre for consideration of surgical management of pulmonary artery aneurysm.

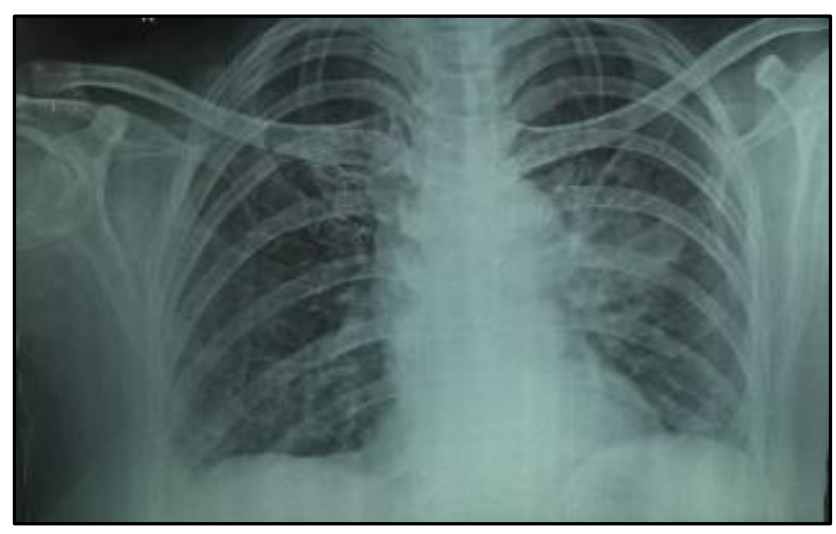

Fig. 1: Showing Left Middle Zone Cavity on Chest X-ray 


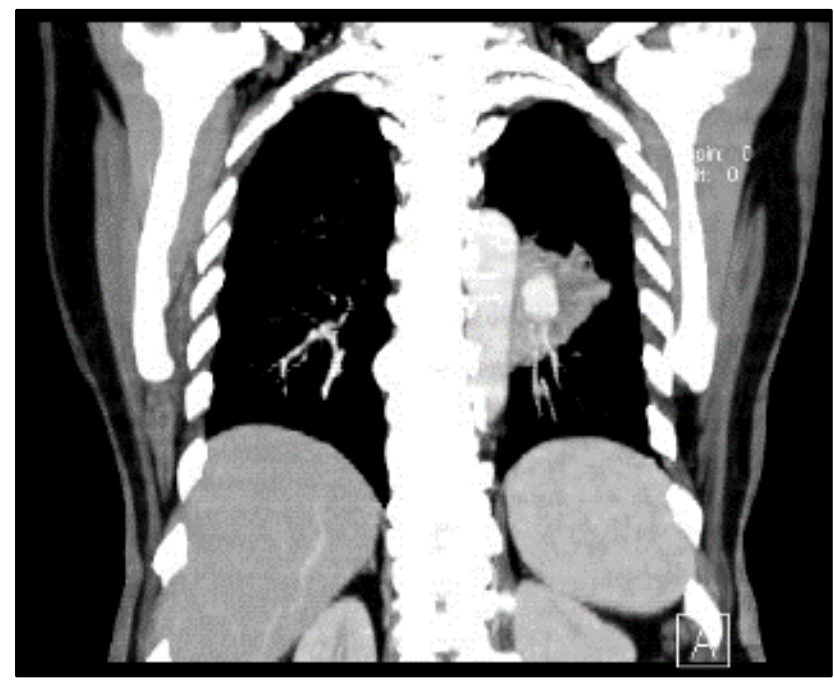

Fig. 2: CECT Chest showing Aneurysm in a Branch of Left Main Pulmonary Artery

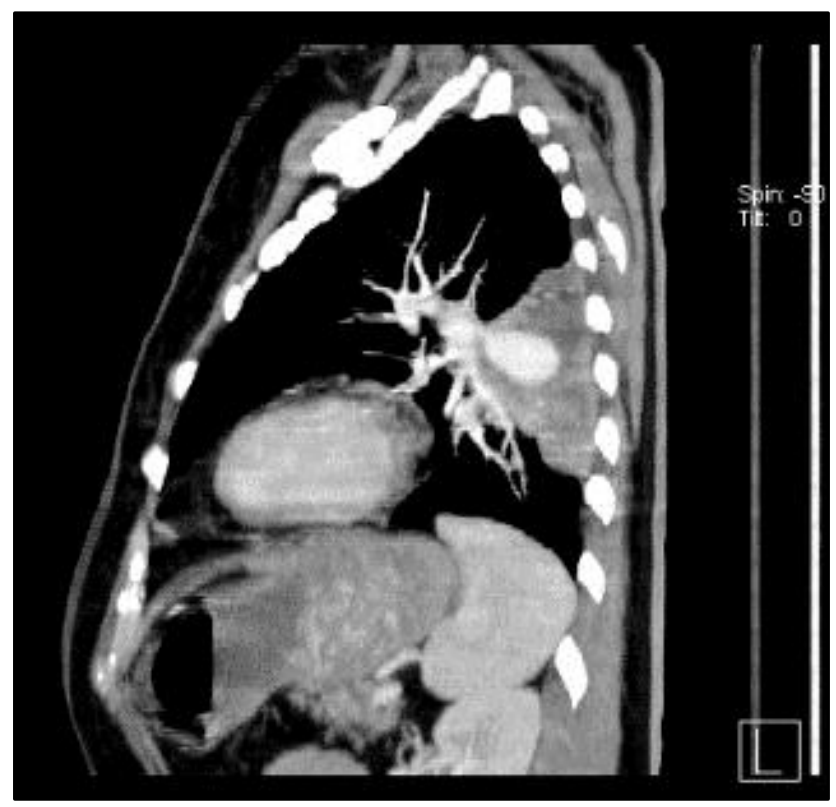

Fig. 3: CECT Chest showing Aneurysm in a Branch of Left Main Pulmonary Artery

\section{DISCUSSION}

Idiopathic pulmonary artery aneurysm is mostly diagnosed in autopsy and has high mortality rate. ${ }^{7}$ The pathological criteria for idiopathic aneurysm are described as, (1) Dilation of pulmonary trunk (involvement of arterial tree might or might not be present), (2) Absence of extra- or intra-cardiac shunts, (3) Absence of pulmonary disease or chronic cardiac disease, and (4) More than minimal atheromatosis or pulmonary vascular tree arteriosclerosis or absence of arterial disease. 8 According to these criteria, the patient had idiopathic pulmonary artery aneurysm.

PAAs can be classified into proximal (or central) PAAs and peripheral PAAs. Proximal PAAs involve the pulmonary trunk and the main right and left PAs. Proximal PAAs are defined as a diameter of over $4 \mathrm{~cm}$ in the PA trunk. ${ }^{9}$ The peripheral PAAs encompass the aneurysms located in the intrapulmonary arteries. In a study of 111 cases with PAA, only 22 cases were identified in the peripheral portion making up for $19.8 \% .^{10}$ Most of the mycotic aneurysms are located in this part. The aneurysms caused by TB were named "Rasmussen aneurysms." 11 In addition to cardiac and pulmonary causes of pulmonary artery hypertension, atherosclerosis, various infections (Syphilis, bacterial endocarditis, tuberculosis), Marfan's syndrome and other connective tissue diseases, cystic medial degeneration, trauma, Behcet's disease and Hughes-Stovin syndrome may lead to PAA.12,13,14 In the majority of cases, mortality occurs due to rupture of the aneurysm.

Thus, corrective surgery is recommended for these patients. However, the risks and long-term outcomes of the surgical treatment has not been well established and it may result in various consequences.12 Dyspnoea, chest pain, haemoptysis and the size of the aneurysm are considered as early signs of rupture, which is a fatal complication.12,14 However, it has been shown that the risk of rupture of the aneurysm is very low in the absence of pulmonary hypertension. In particular, increased pulmonary flow and increased pulmonary artery pressure in patients with PAA due to the left-to-right shunt raise the risk of rupture. ${ }^{15}$

\section{REFERENCES}

1. Serasli E, Antoniadou M, Steiropoulos P, et al. Lowpressure pulmonary artery aneurysm presenting with pulmonary embolism: a case series. Journal of Medical Case Reports 2011;5:163.

2. Muthialu N, Raju V, Muthubaskaran V, et al. Idiopathic pulmonary artery aneurysm with pulmonary regurgitation. Annals of Thoracic Surgery 2010;90(6):2049-51.

3. Araujo, Escribano P, Lopez-Gude MJ, et al. Giant pulmonary artery aneurysm in a patient with vasoreactive pulmonary hypertension: a case report. BMC Cardiovascular Disorders 2011;11:64.

4. Nguyen ET, Silva CIS, Seely JM, et al. Pulmonary artery aneurysms and pseudoaneurysms in adults: findings at CT and radiography. American Journal of Roentgenology 2007;188(2):126-34.

5. Zhao YJ, Cheng XS. An analysis of 21 cases of idiopathic dilatation of the pulmonary artery. Zhonghua Nei Ke Za Zhi 1992;31(1):24-5.

6. Dayığlu E, Sever $K$, Başaran $M$, et al. Idiopathic pulmonary artery aneurysm. Indian J Thorac Cardiovasc Surg 2004;20:140-1.

7. Orman G, Guvenc TS, Balci B, et al. Idiopathic pulmonary artery aneurysm. Annals of Thoracic Surgery 2013;95(2):33-4.

8. Van Rens MT, Westermann CJ, Postmus PE, et al. Untreated idiopathic aneurysm of the pulmonary artery; long-term follow-up. Respiratory Medicine 2000;94(4):404-5.

9. Barbour DJ, Roberts WC. Aneurysm of the pulmonary trunk unassociated with intracardiac or great vessel leftto-right shunting. Am J Cardiol 1987;59(1):192-4.

10. Boyd LJ, McGravack TH. Aneurysm of pulmonary artery. Am Heart J 1939;18:562-78.

11. Ungaro R, Saab S, Almond CH, et al. Solitary peripheral pulmonary artery aneurysms pathogenesis and surgical treatment. J Thorac Cardiovasc Surg 1976;71(4):566-71.

12. Bartter T, Irwin RS, Nash G. Aneurysms of the pulmonary arteries. Chest 1988;94(5):1065-75. 
13. Imazio M, Cecchi E, Giammaria M, et al. Main pulmonary artery aneurysm: a case report and review of the literature. Ital Heart J 2004;5(3):232-7.

14. Durieux P, Bletry O, Huchon G, et al. Multiple pulmonary arterial aneurysms in behcet's disease and hughes-stovin syndrome. Am J Med 1981;71(4):736-41.
15. Graham JK, Shehata B. Sudden death due to dissecting pulmonary artery aneurysm: a case report and review of the literature. Am J Forensic Med Pathol 2007;28(4):342-4. 